\title{
A QUESTÃO DO GÊNERO COMO CATEGORIA HISTÓRICA DE ANÁLISE NA BUSCA DA EFETIVAÇÃO DO ESTADO DEMOCRÁTICO DE DIREITO
}

\author{
Lusia Ribeiro Pereira ${ }^{1}$
}

\section{DEFININDO O PROBLEMA A SER INVESTIGADO OU DA PERMANÊNCIA DOS PROCESSOS DE SUBMIÇÃO DA MULHER}

\begin{abstract}
"A mulher deve adorar o homem como a uma deus. Toda manhã, por nove vezes consecutivas, deve ajoelhar-se aos pés do marido e, braços cruzados, perguntar-lhe : senhor, que desejais que eu faça?" (Zaratustra - filósofo persa, sec, VII a. C.)
\end{abstract}

"Quando um homem for repreendido em público por uma mulher, cabe-lhe o direito de derrubá-la com um soco, desferir-lhe um pontapé e quebrar-lhe o nariz para que assim, desfigurada, não se deixe ver, envergonhada de sua face. E é bem merecido, por dirigir-se ao homem com maldade de linguajar ousado",

(Le Ménagier de Paris, Tratado de Conduta Moral e Costumes da França, sec. XIV.)

“Os homens são superiores às mulheres porquê Alá outorgou-lhes a primazia sobre elas. Portanto, dai aos varôes o dobro do que dai às mulhres. Os maridos que sofrem desobediência de suas mulhres podem castigá-las: deixá-las sós em em seus leitos, e até bater nelas. Não se legou ao homem maior calamidade que a mulher."

(Alcorão, livro Sagrado dos Mulçumanos, recitado por Alá a Maomé no sec. VI).

"Que as mulheres estejam caladas nas Igrejas porque não lhes é permitido falar". Se quiserem ser instruídas sobre algum ponto, interroguem em casa os seus maridos.”“.

(São Paulo, apóstlo cristão, ano 67 D.C).

"Todas as mulhres que seduzirem e levarem ao casamento os súditos de sua Majestade mediante o uso de perfumes, pinturas, dentes postiços, perucas e recheio nos quadris, incorrem em delito de bruxaria e o casamento fica automaticamente anulado".

(Constituição Nacional Inglesa, lei do Sec. XVIII).

"Mesmo que a conduta do marido seja sensurável, mesmo que este se dê a outros amores, a mulher virtuosa deve reverenciá-lo como a um deus. Durante a infância, uma mulher deve depender de seu pai, ao se casar de seu marido, se este morrer, de seus filhos e se não os tiver, de seu soberano. Uma muçher nunca deve governar a si própria. (Leis de Manu, livro sagrado da Índia)".

"As crianças, os idiotas, os lunáticos e as mulhres não podem e não têm capacidade para efetuar negócios".

\footnotetext{
${ }^{1}$ Este texto surgiu originalmente da tese de doutoramento apresentada na Faculdade de Educação da USP/1997 sob o título: De Donzela Angelical e Esposa Dedicada a Profissional da Educação - a presença do discurso religioso na formação da mulher professora. Após o doutoramento ingressei como professora de metodologia científica no curso de Direito (graduação, mestrado e doutorado) na Pontífícia Universidade Católica de Minas Gerais, campus Coração Eucarístico, (Belo Horizonte) onde a elaboração de trabalhos acadêmicos, monografias, dissertações ou teses a partir de pesquisa com uso de dados históricos têm sido recorrente. Para fins de apresentação desse texto está sendo proposta a abordagem da questão do gênero como uma categoria histórica de análise na busca de efetivação do Estado Democrático de Direito, problema esse que se apresenta como relevante pricipalmente após a promulgação da Lei Maria da Penha (Lei 11.340/2006).
} 
(Henrique VII, rei da Inglaterra, chefe da Igreja Anglicana, sec. XVI).

"O pior adorno que uma mulher pode querer é ser sábia."

(Lutero, teólogo alemão, reformador protestante, sec. XVI.)

As afirmações acima poderiam ser consideradas como folclore se não estivessem em certa medida presentes no cotidiano do sujeitos sociais nesse final de século XX e início do século XXI.

Um processo de investigação tem por objetivo mapear uma problemática a ser estudada e, ao mesmo tempo, apontar a sua relação com o passado ou, ainda, auxiliar no exercício de trazer à tona um presente em tão longa duração. Na questão das relações de gênero e nesta referindo apenas à posição da mulher na sociedade, os textos acima nos remetem a um passado distante. Porém esse passa não está de todo apagado e o mesmo 'resta' presente em práticas sociais presentes no mundo contemporâneo. Nas relações de trabalho a mulher ocupa ainda um papel inferior ao do homem, seja em questões salariais, de promoção ou de demissão. Ao homem ainda é concedido o papel de construtor e provedor da sociedade. Observando o cotidiano, a forma comum de se pautar a vida nos diversos espaços sociais, ainda podem ser encontrados comportamentos que nos remetem aos textos 'antigos' aqui postados.

Uma inferência que pode ser feita, tendo como princípio a análise histórica, é que a relação passado - presente não são independentes entre si. O Passado se resvala no presente impregnando-o e se prolongando dentro dele. Isso nos permite compreender como determinas práticas sócias que aparentemente julgamos ultrapassadas aparecem e permeiam as mais simples relações do cotidiano. Isso se torna mais evidente quando essas relações são construídas em bases culturais extremamente fortes e duradouras. As relações homem mulher são culturais e fortemente construídas no campo do simbolismo de pode e religioso.

Assim estas questões para serem compreendidas necessitam de uma incursão teórica que as pontuem no lugar onde elas se constroem.

\section{2 - A QUESTÃo DO GÊNERO COMO UMA CATEGORIA DE ANÁLISE}

O gênero como uma categoria de análise no seio das Ciências Sociais vem-se constituindo como uma prática rotineira.

A introdução da categoria gênero significa perceber as relações entre homens e mulheres como sendo social, histórica e culturalmente construída. Isto significa que o ser e o estar no mundo como homem ou mulher não é algo apenas natural e biologicamente determinado, mas, também, pertence à ordem do social e do cultural e, assim sendo, tais 
papéis se alteram no decorrer do processo histórico e também em função de outras determinações sociais como a classe e a raça. Tais categorias não se encontram separadas no contexto das diversas formações sociais, mas profundamente entrelaçadas entre si. $\mathrm{Na}$ educação, também, essas categorias se encontram em estreita articulação. A introdução dessas categorias abre, portanto, novas perspectivas para se compreenderem as questões da educação, em relação às suas rupturas ou suas permanências.A categoria gênero ainda permite lançar um olhar sobre a escola como sendo um local de trabalho feminino, daí emergindo questões como, por exemplo, qual é o fazer feminino que aí se constitui e vai-se constituindo no decorrer do processo histórico. A categoria gênero aplicada à análise da prática educativa escolar implica, pois, reconhecer que o corpo docente é sexuado, abandonando o masculino genérico e deixando aflorar as especificidades que marcam as relações sociais no interior das escolas, bem como as questões históricas que levaram as mulheres a se tornarem professoras.

Ao eleger o gênero como categoria de análise para discutir as relações educativas escolares ou as relações históricas presentes na formação da sociedade é necessário mais que uma análise classificatória. No sentido colocado por Joan Scott (1990) gênero seria "uma maneira de se referir à organização social entre os sexos”. (p.05). Isto dá a essa organização uma perspectiva relacional na compreensão dos exercícios sociais dos papéis vivenciados tanto pelos homens quanto pelas mulheres, em que um não se constitui sem a presença do outro. Neste sentido, falar de papéis femininos traz implícita uma fala sobre papéis exercidos tanto pelos homens como pelas mulheres. Falar de papéis femininos traz implícita uma fala sobre papéis masculinos. Não tanto no sentido da constatação de campos de poder e relações de força, mas, muito mais, no sentido de procurar explicitar a constituição histórica da identidade de homens e mulheres a partir da inserção destes numa dada ordem sócio-cultural em que experiências são vividas de forma relacional, quer no hoje quer no passado. E no desafio de estabelecimento de relações entre esse passado e o presente, procurando significado para as práticas sociais que envolvem os homens e as mulheres hoje. Isto significa superar

tentativas de teorização do gênero que não conseguiram sair dos quadros tradicionais das ciências sociais (...) que propõem explicações causais universais. (Joan Scott, op. cit. p.07).

As explicações universais tendem a uma simplificação das relações reduzindo-as à mera descrição dos sujeitos sociais, sem, contudo, nomeá-los, situá-los numa dada configuração social perpassada por laços culturais e históricos. 
A superação dessas análises universalistas, a partir da utilização da categoria gênero, implica rejeitar preconceitos ainda existentes nos meios acadêmicos, particularmente entre os historiadores e operadores de Direito para quem gênero se refere unicamente a "estudo de mulheres", perpetuando o mito de que um nada tem que ver com o outro, o que contribui para a permanência de visões estereotipadas de homem e de mulher.

Essa superação implica um esforço que vise a aprimorar as teorias que dão sustentação às análises sociais a partir do gênero. Tal processo significa dar atenção aos discursos ideológicos sobre as representações de gênero nos quais o mundo privado, doméstico, pertence à mulher, a ela competindo cuidar de crianças, velhos e doentes; e o mundo público, lugar das decisões políticas, como pertencente ao homem, perpetuando a idéia do mundo como um ordenamento masculino.

No campo das investigações e pesquisas na área do Direito é preciso um esforço para se decodificar a dimensão simbólica da linguagem, dos gestos e das atitudes que acompanham os processos de interação social de meninos e meninas, seja na sociedade em geral, seja no âmbito da aplicação da justiça.

Numa pesquisa desta problemática deve-se levar em conta os conceitos normativos que, utilizando-se das interpretações simbólicas, colocam normas de comportamento para as mulheres, a partir de "doutrinas religiosas, educativas, científicas, políticas ou jurídicas”. (id. P.14) sem, contudo, contextualizar esses aspectos normativos, apresentando-os como norma consensual, sem levar em conta os aspectos de rejeição e conflito presentes no cumprimento dessas normas, o que buscaria demonstrar que elas seriam cumpridas sem contestação.

Outro aspecto diz respeito à noção de política, considerando os fundamentos da organização social para além dos sistemas de parentesco, mas levando em consideração que:

\footnotetext{
um mercado de trabalho sexualmente segregado faz parte do processo de construção do gênero, as instituiçães de educação somente masculinas, não mistas, ou de coeducação fazem parte do mesmo processo de construção do gênero. (id. p.15)
}

E, por fim, a identidade subjetiva, que poderia ser entendida como a própria forma de se compreenderem e se considerarem internalizadas pelas próprias mulheres. Sobre essa questão, a psicanálise tem fornecido grandes contribuições, o que, atualmente, vem ganhando expressão na formação dos operadores do Direito, não se dispensando análises históricas mais contextualizadas.

A questão gênero, longe de ser uma simplificação nos processos de investigação das relações históricas que marcam a instituição da sociedade, coloca novos desafios, novos horizontes, novas fontes e novas abordagens de questões já antes visitadas, mas que ainda se 
fazem necessárias de serem estudadas e analisadas. É nessa perspectiva que Guacira Louro (1992) propõe formas de encaminhamento nesse processo de investigação, no sentido de se proceder a uma leitura da História da Educação (e também na História do Direito) em que os atores sejam sujeitos concretos, com corpo, raça e gênero e ainda, desejos, sentimentos, paixões, gostos, escolhas. Que sejam contempladas as especificidades históricas e culturais da construção social das relações entre os gêneros e que também sejam percebidas as acomodações e resistências dos homens e das mulheres às suas próprias condições objetivas de existência.

Um dos objetivos, pois, da pesquisa histórica, é romper com essa fixidez, procurando nos processos sociais de hoje a sua dimensão de historicidade presente no movimento de mudança e permanência. É desnaturalizar a ordem social, colocando-a na dimensão do histórico em que é possível perceber a ação humana que a constrói, tanto no hoje como no ontem.

Escrever história é uma ação reflexiva que fornece regras para a ação, à medida que esse exercício se torna uma (re) interpretação daquilo que foi vivido e experimentado como experiência humana. É uma busca do testamento de nossa ação (Hannah Arendt, 1992), reconciliando o presente com o passado e abrindo possibilidades ao homem e à mulher de reconciliarem-se com sua realidade. E, para isso, o passado tem de deixar de ser visto como um fardo. Ou como bem coloca Hannah Arendt

\begin{abstract}
A primeira coisa a ser observada é que não apenas o futuro - a onda do futuro - mas também o passado, é visto como uma força, e não, como em praticamente todas as nossas metáforas, como um fardo com que o homem (e a mulher) tem de arcar e de cujo peso morto os vivos podem ou mesmo devem se desfazer em sua marcha para o futuro. Nas palavras de Faulkner: 'o passado nunca está morto, ele nem mesmo é passado'. Esse passado, além do mais, estirando-se por todo seu trajeto de volta à origem, ao invés de puxar para trás, empurra para frente, e, ao contrário do que seria de esperar, é o futuro que nos impele de voltar ao passado. (op. cit. P.37)
\end{abstract}

Apropriar-se do passado é o esforço de pavimentar de novo o presente. Este é o papel do (a) historiador (a), e também do operador do Direito, pois é com o presente que ele(a) tem a ver à medida que, ao escrever a história, faz com o passado um acerto de contas, colocando o presente numa situação crítica, "explodindo com seu continuum" no desocultamento do passado que insiste em se perpetuar no presente. Isso é um compromisso da história. Um Compromisso da Justíça. Compromisso que se revela e se expõe, à medida que, na análise histórica, fica contemplada a relação passado/presente como peças de uma mesma engrenagem. É o hoje interrogando o ontem, porque aquele está saturado de pregnâncias deste. E são essas pregnâncias do presente que exigem que se façam releituras do passado, 
não como realidade acabada, mas como algo que, tendo sido determinado, continua, de certa forma, sendo determinante. E é nesse sentido que se torna necessário fazer perguntas ao passado. Outras perguntas, a partir de novos problemas que se apreendem no presente. E para isso, o (a) historiador (a) precisa estar preocupado (a), engajado (a) com os problemas de hoje para que possa tratar o passado como realidade viva, porque ainda estruturante de um presente.

Escandir essas histórias é fazer uma outra leitura por baixo desse amontoado de acontecimentos, fatos, leis. É considerar que nada, ou nenhum objeto é totalmente linear, mas que o objeto, nos seus vários passados, várias formas de ser podem ser estudados e anlisados por pesquisadores de todas as áreas.

Assim, os acontecimentos discursivos, devem ser considerados tal como objeto de análise para se compreender melhor a história da formação da relação mulher-homem e, a partir daí, estabelecer um outro viés pelo qual seja possível elucidar melhor o seu "rosto", a sua identidade social. Esses não são fragmentos isolados dentro de uma certa formação social. Mas acontecimentos discursivos que, enquanto rastros, estiveram presentes na constituição da história de sujeitos sociais e fazem parte de um sistema de relações que se simbolizam mutuamente. Ou, ainda, é possível dizer que a sua historicidade está imbricada nas estruturas políticas, econômicas, culturais, sob uma forma de continuidade e descontinuidade, regularidades e rupturas, singularidades e generalidades, o que vale dizer que procurar perceber os acontecimentos discursivos na sua forma histórica de existir e fazer história.

Assim, na pesquisa inicial que original a tese de doutoramento, partindo da performance das mulheres-professoras e de suas práticas, de como elas se qualificam e qualificam sua ação educativa, de como elas agem no dia-a-dia da escola, do que priorizam, do que dizem e escrevem, é que fui em busca dos discursos produzidos sobre elas. Não para conhecer e julgar esses discursos. Eles pertencem à história. E à história não se fazem julgamentos. Mas fui em busca deles para procurar entender um pouco mais a mulherprofessora e sua ação educativa. E essa é a pergunta que fiz aos discursos, ao tentar dar visibilidade aos enunciados: Quem é essa professora?

\section{3 - O PROCESSO DE INVESTIGAÇÃO DIALOGANDO COM OS ARQUIVOS}

Ao eleger o gênero como categoria de análise para discutir as relações educativas escolares ou as relações históricas presentes na formação da sociedade, é necessário mais que uma análise classificatória. No sentido colocado por Joan Scott (1990) gênero seria "uma maneira de se referir à organização social entre os sexos”. (p.05). Isto dá a essa organização 
uma perspectiva relacional na compreensão dos exercícios sociais dos papéis vivenciados tanto pelos homens quanto pelas mulheres, em que um não se constitui sem a presença do outro. Neste sentido, falar de papéis femininos traz implícita uma fala sobre papéis exercidos tanto pelos homens como pelas mulheres. Falar de papéis femininos traz implícita uma fala sobre papéis masculinos. Não tanto no sentido da constatação de campos de poder e relações de força, mas, muito mais, no sentido de procurar explicitar a constituição histórica da identidade de homens e mulheres a partir da inserção destes numa dada ordem sócio-cultural em que experiências são vividas de forma relacional, quer no hoje quer no passado. E no desafio de estabelecimento de relações entre esse passado e o presente, procurando significado para as práticas sociais que envolvem os homens e as mulheres hoje. Isto significa superar

tentativas de teorização do gênero que não conseguiram sair dos quadros tradicionais das ciências sociais (...) que propõem explicações causais universais. (Joan Scott, op. cit. p.07).

As explicações universais tendem a uma simplificação das relações reduzindo-as à mera descrição dos sujeitos sociais, sem, contudo, nomeá-los, situá-los numa dada configuração social perpassada por laços culturais e históricos.

A superação dessas análises universalistas, a partir da utilização da categoria gênero, implica rejeitar preconceitos ainda existentes nos meios acadêmicos, particularmente entre os historiadores, ( e os operadores de Direito ) para quem gênero se refere unicamente a "estudo de mulheres", perpetuando o mito de que um nada tem que ver com o outro, o que contribui para a permanência de visões estereotipadas de homem e de mulher. Essa superação implica um esforço que vise a aprimorar as teorias que dão sustentação às análises sociais a partir do gênero. Tal processo significa dar atenção aos discursos ideológicos sobre as representações de gênero nos quais o mundo privado, doméstico, pertence à mulher, a ela competindo cuidar de crianças, velhos e doentes; e o mundo público, lugar das decisões políticas, como pertencente ao homem, perpetuando a idéia do mundo como um ordenamento masculino. No campo das investigações e pesquisas na área do Direito é preciso um esforço para se decodificar a dimensão simbólica da linguagem, dos gestos e das atitudes que acompanham os processos de interação social de meninos e meninas, seja na sociedade em geral, seja no âmbito da aplicação da justiça.

Numa pesquisa desta problemática deve-se levar em conta os conceitos normativos que, utilizando-se das interpretações simbólicas, colocam normas de comportamento para as mulheres, a partir de doutrinas religiosas, educativas, científicas, políticas ou jurídicas. sem, 
contudo, contextualizar esses aspectos normativos, apresentando-os como norma consensual, sem levar em conta os aspectos de rejeição e conflito presentes no cumprimento dessas normas, o que buscaria demonstrar que elas seriam cumpridas sem contestação.

Outro aspecto diz respeito à noção de política, considerando os fundamentos da organização social para além dos sistemas de parentesco, mas levando em consideração que:

um mercado de trabalho sexualmente segregado faz parte do processo de construção do gênero, as instituições de educação somente masculinas, não mistas, ou de coeducação fazem parte do mesmo processo de construção do gênero. (id. p.15)

E, por fim, a identidade subjetiva, que poderia ser entendida como a própria forma de se compreenderem e se considerarem internalizadas pelas próprias mulheres. Sobre essa questão, a psicanálise tem fornecido grandes contribuições, o que, atualmente, vem ganhando expressão na formação dos operadores do Direito, não se dispensando análises históricas mais contextualizadas. Nesse sentido,

os historiadores devem antes de tudo examinar as maneiras pelas quais as identidades de gênero são realmente construídas e relacionar seus achados com toda uma série de atividades, de organizações e representações sociais historicamente situadas. (id. p.15)

A questão gênero, longe de ser uma simplificação nos processos de investigação das relações históricas que marcam a instituição social, coloca novos desafios, novos horizontes, novas fontes e novas abordagens de questões já antes visitadas, mas que ainda se fazem necessárias de serem estudadas e analisadas. É nessa perspectiva que Guacira Louro (1992) propõe formas de encaminhamento nesse processo de investigação, no sentido de se proceder a uma leitura da História da Educação em que os atores sejam sujeitos concretos, com corpo, raça e gênero e ainda, desejos, sentimentos, paixões, gostos, escolhas. Que sejam contempladas as especificidades históricas e culturais da construção social das relações entre os gêneros e que também sejam percebidas as acomodações e resistências dos homens e das mulheres às suas próprias condições objetivas de existência. Uma investigação que leve em conta que

no processo de educação, há portanto um conjunto bastante complexo e contraditório de expectativas e de atribuições designadas para cada um dos gêneros, e ao(à) historiador(a) cabe estar atento(a) à complexidade desse processo. Com isso estou acenando para uma leitura mais ampliada da educação dos sujeitos, ou seja, suponho que também interessa ao estudioso(a) da educação processos que estão fora da escola, para além dela, mas que de um modo ou de outro acabam por atravessá-la. (p. 63) 
Uma escrita da História não pode ignorar as condições objetivas sobre as quais ocorre a educação. Particularmente quando se trata da educação da mulher. Nesse caso, as confissões religiosas têm papel privilegiado na fundação e manutenção das escolas femininas, católicas na sua maioria, mas também é expressiva a presença protestante nessa atividade de ensino. A história escrita da educação brasileira fornece dados bastante concretos sobre esse assunto (Otaísa Romanelli 1987, Ana Maria Freire 1989 para citar apenas dois trabalhos bastante conhecidos entre os/as educadores(as). E por reconhecer a forte presença das escolas confessionais na formação da mulher, sobretudo da professora é que escolhi trazer à tona o discurso religioso que perpassa esta educação, em especial o que faz referência aos conceitos de educação e educador(a) e aos papéis da mulher e da professora.

Assim também os operadores (as) do direito não podem ignorar a formação histórico social inscrita nas relações entre os sujeitos. Escandir a internalização dos discursos, pesquisando histórias pessoais, documentos oficiais, arquivos particulares e institucioanais, fotografias, jornais, revistas numa perspectiva histórico temporal é uma das possibilidades que se apresentam para compreender como homens e mulheres internalisam sua forma de ser e estarem no mundo como sujeitos sociais.

\section{REFERÊNCIAS}

ALVES, Rubem. Conversas com quem gosta de ensinar. São Paulo: Cortez Autores Associados, 1983. 87p.

AZEVEDO, Gilka Vincentini Ferreira de (Comp.). Do ensino de $\mathbf{1}^{\mathbf{0}}$ grau; legislação e pareceres. Brasília, Ministério da Educação e Cultura, Departamento de Documentação e Divulgação, 1979. 575p.

BALDIN, Nelma. O ensino da História; uma prática que ultrapassa os muros da escola pública. São Paulo: Pontifícia Universidade Católica, 1985. 423p. (Tese, Doutorado).

BAUDELOT, Christian \& ESTABLET, Roger. La escuela capitalista. 6. ed. Madrid: Siglo Veintiuno, 1980. 300p.

BLOCH, Marc. Introdução à História. 4. ed. s.l., Europa-América, s.d. 179p.

BLOOM, Benjamin et al. Taxionomia de objetivos educacionais; domínio cognitivo. Porto Alegre: Globo, 1973. v. 1.

BORGES, Vavy Pacheco. O ensino de História. Projeto História, São Paulo (4): 63-4, jun. 1985.

O que é história. 5. ed. São Paulo: Brasiliense, 1983. 84p. 
BOURDIEU, Pierre \& PASSERON, Jean-Claude. A reprodução; elementos para uma teoria do sistema de ensino. 2. ed. Rio de Janeiro: F. Alves, 1982. 238p.

BRANDÃO, Carlos Rodrigues (Org.). A questão política da educação popular. São Paulo: Brasiliense, 1982. 198p.

BRASIL. Leis, decretos, etc. Lei n. 7.486, 6 de jan. 1986. Aprova as diretrizes do Primeiro Plano Nacional de Desenvolvimento (PND) da Nova República, para o período de 1986 a 1989, e dá outras providências. Diário Oficial, Brasília, n. 109, 12 jun. 1986. Seção 1, p. 8473-531.

BRAUDEL, Fernand. Escritos sobre a História. São Paulo: Perspectiva, 1969. 294p.

BRITES, Olga. A criança e a História que lhe é ensinada. Revista Brasileira de História, São Paulo, 5(10): 247-50, mar. / ago. 1985.

CADERNOS Faculdade de Educação UFMG. Estudos Sociais em questão. Belo Horizonte, n. 2 , out. 1985 .

CARDOSO, Ciro. Flamorion \&. Uma introdução à história. 3. ed. São Paulo: Brasiliense, 1983a. 124p.

CARDOSO, Ciro Flamarion S. \& BRIGNOLI, Hector Perez. Os métodos da História. 3. ed. Rio de Janeiro: Zahar, 1983b. 528p.

CARR, E. H. Que é história. 3. ed. Rio de Janeiro: Paz e Terra, 1982. 129p.

CENTRO de Documentação e Informações Educacionais - CEDINE, Belo Horizonte. Evasão imediata. Belo Horizonte, 1985. 16p. (CEDINE Informa, 3).

CHAUÍ, Marilena de Souza. História a contrapelo. In: DE DECCA, Edgar Salvadori. O silêncio dos vencidos. 2. ed. São Paulo: Brasiliense, 1984. p. 11-28.

O que é ideologia. 12. ed. São Paulo: Brasiliense, 1983. 125p.

CURY, Carlos Roberto Jamil. Educação e contradição; elementos metodológicos para uma teoria crítica do fenômeno educativo. São Paulo: Cortez Autores Associados, 1985. $134 \mathrm{p}$.

Ideologia e educação brasileira. São Paulo: Cortez \& Moraes, 1978. 201p.

DE DECCA, Edgar Salvadori. O silêncio dos vencidos. 2. ed. São Paulo: Brasiliense, 1984. 209p.

DEL PRIORI, Mary. Histórias Íntima: sexualidade e erotismo na história do Brasil. São Paulo: Editora Planeta do Brasil, 2011.

DIRETRIZES Gerais da Política Educacional Mineira, 1984/87. s.n.t. (Mimeogr.) (Trabalho apresentado no Encontro de Técnicos da SEE e DRE, 5, Belo Horizonte, 1986).

FAZENDA, Ivani Catarina Arantes. Educação no Brasil anos 60; o pacto do silêncio. São Paulo: Loyola, 1985. 126p. 
FEBVRE, Lucien. Combates pela História. 2. ed. Lisboa: Presença, 1985. 262p.

FENELON, Déa Ribeiro. A formação do profissional de História e a realidade do ensino. Cadernos CEDES, Campinas (8): 24-31, 1982.

Trabalho, cultura e história social; perspectivas de investigação. Projeto História, São Paulo (4): 21-37, jun. 1985.

FERRO, Marc. A manipulação da História no ensino e nos meios de comunicação. São Paulo: IBRASA, 1983. 306p.

FRIGOTTO, Gaudêncio. A produtividade da escola improdutiva; um (re)exame das relações entre educação e estrutura econômico-social capitalista. São Paulo: Cortez Autores Associados, 1984. 235p.

GARDINER, Patrick. Teorias da História. 3. ed. Lisboa: Fundação Calouste Gulbenkian, 1964. 679p.

GHIRALDELLI JR., Paulo. A vara teimosa; debatendo com Paolo Nosella. Educação \& Sociedade, Campinas, 8(24):116-45, ago. 1986.

GOLDMANN, Lucien. Dialética e cultura. 2. ed. Rio de Janeiro: Paz e Terra, 1979. 197p.

GOMES, Paulo Miranda. História do Brasil; $\mathbf{5}^{\mathbf{a}}$ série - $\mathbf{1}^{\mathbf{0}}$ grau. Belo Horizonte: Lê, 1981. $102 \mathrm{p}$.

GORZ, André. Crítica da divisão do trabalho. São Paulo: M. Fontes, 1980. 247p.

GRAMSCI, Antônio. Concepção dialética da História. 4. ed. Rio de Janeiro: Civilização Brasileira, 1981. 341p.

HESPANHA, Antonio Manuel. Imbecilitas: As bem-aventuranças da inferioridade nas sociedades de Antigo Regime. Annablume Editora, S.P.,Brasil, 2010.

KOSIK, Karel. Dialética do concreto. 2. ed. Rio de Janeiro: Paz e Terra, 1976. 230p.

LE GOFF, Jacques. História. In: ENCICLOPÉDIA EinaudI; memória-história. s.l., Imprensa Nacional - Casa da Moeda, 1984. v. 1, p. 158-259.

Memória. In: ENCICLOPÉDIA EINAUDI; memória-história. s.l., Imprensa Nacional Casa da Moeda, 1984. v.1, p. 11-50.

Passado/presente. In: ENCICLOPÉDIA EINAUDI; memória-história. s.1., Imprensa Nacional - Casa da Moeda, 1984. v.1, p. 293-310.

Reflexões sobre a História. Lisboa, Edições 70, 1982. 112p.

LE GOFF, Jacques \& NORA, Pierre. História; novas abordagens. Rio de Janeiro: F. Alves, 1976. 200p.

História; novos objetos. Rio de Janeiro: F. Alves, 1976. 238p.

História; novos problemas. Rio de Janeiro: F. Alves, 1976. 193p.

Revista da Faculdade Mineira de Direito, v.13, n. 25, jan./jun. 2010 - ISSN 1808-9429. 
LE GOFF, Jacques et al. A nova história. Lisboa: Edições 70, 1977. 89p.

LOPES, Eliane Marta Santos Teixeira. Colonizador-colonizado; uma relação educativa no movimento da história. Belo Horizonte: UFMG, 1985. 259p.

A publicização da instrução no contexto histórico do século XVIII; um estudo de caso da relação Educação - Sociedade. Belo Horizonte, Faculdade de Educação da UFMG, 1980. 187p. (Dissertação, Mestrado).

LOWY, Michael. Ideologias e ciência social; elementos para uma análise marxista. São Paulo: Cortez Autores Associados, 1985. 112p.

Método dialético e teoria política. Rio de Janeiro: Paz e Terra, 1975. 142p.

LUKACS, György. História e consciência de classe; estudo de dialética marxista. Porto: Escorpião, 1974. 378p.

MACHADO, Jónatas Eduardo Mendes. Liberdade Religiosa Numa Comunidade Constitucional Inclusiva: dos direitos da verdade aos direitos dos cidadãos. Coimbra Editora, 1996.

MARX, Karl. Contribuição à crítica da economia política. São Paulo: M. Fontes, 1977. $351 \mathrm{p}$.

O processo de produção do capital. In: MARX, Karl. O capital; crítica da economia política. 8. ed. São Paulo: Difel, 1982. Livro 1, v. 1, 579p.

MARX, Karl \& ENGELS, Friedrich. A ideologia alemã. São Paulo: Hucitec, 1984. 138p.

Textos sobre educação e ensino. Lisboa: Moraes, 1983. 98p.

MINAS GERAIS. Leis, decretos, etc. Decreto no 14.810, 15 set. 1972. Regimento do Conselho Estadual de Educação. Lemi Revista Jurídica, Belo Horizonte, 5(59): 2348-59, out. 1972.

MINAS GERAIS. Leis, decretos, etc. Decreto $\mathbf{n}^{\mathbf{0}}$ 18.749, 13 out. 1977. Dispõe o sistema operacional de educação. Informativo MAI de Ensino do Estado de Minas Gerais, Belo Horizonte, 4(23): 10-25, nov. 1977.

MINAS GERAIS. Leis, decretos, etc. Lei Delegada $\mathbf{n}^{\mathbf{0}}$ 31-28 ago. 1985. Reorganiza o Conselho Estadual de Educação e dá outras providências. Informativo MAI de Ensino do Estado de Minas Gerais, Belo Horizonte, (117): 8-12, set. 1985.

MINAS GERAIS. Secretaria de Estado da Educação. Estudos Sociais; programas de ensino de $\mathbf{1}^{\mathbf{o}}$ e $2^{\mathbf{o}}$ graus. Informativo MAI de Ensino do Estado de Minas Gerais, Belo Horizonte, (10): 9-170, out. 1974.

MINAS GERAIS. Secretaria de Estado da Educação. Superintendência Educacional.

Diretoria do Ensino de $1^{\mathrm{o}}$ grau. Considerações sobre educação e trabalho no currículo do ensino de $1^{\circ}$ grau. Belo Horizonte, 1984. 40p. 
MORAES, Antônio Carlos Roberto \& COSTA, Wanderley Messias da. A valorização do espaço. São Paulo: Hucitec, 1984. 196p.

NOSELLA, Paolo. Educação tradicional e educação moderna. Educação \& Sociedade, Campinas, 8 (23): 106-35, abr. 1986.

OLIVEIRA, Betty A. \& DUARTE, Newton. Socialização do saber na escola. São Paulo: Cortez Autores Associados, 1985. 103p.

História Geral - moderna e contemporânea; $8^{a}$ série. São Paulo: IBEP, 1980. 199p.

PLANO Mineiro de Educação 1984/87. Informativo MAI de Ensino de Estado de Minas Gerais, Belo Horizonte (102-103): 132-67, jun. / jul. 1984.

RODRIGUES, José Honório. Filosofia e história. Rio de Janeiro: Nova Fronteira, 1981. $129 \mathrm{p}$.

História, corpo do tempo. São Paulo: Perspectiva, 1984. 282p.

SANCHEZ VÁZQUEZ, Adolfo. Filosofia da práxis. 2. ed. Rio de Janeiro: Paz e Terra, 1977. 454p.

SANTOS, Boaventura de Sousa. A Gramática do Tempo: para uma nova cultura política. São Paulo: Cortez,2010.

SANTOS, Boaventura, MENESES, Maria Paula, Org. Epistemologias do Sul. São Paulo: Cortez, 2010.

SAVIANI, Dermeval. Educação: do senso comum à consciência filosófica. São Paulo: Cortez Autores Associados, 1982. 224p.

Escola e democracia. 5. ed. São Paulo: Cortez Autores Associados, 1984. 96p.

SCHAFF, Adam. História e verdade. 2. ed. São Paulo: M. Fontes, 1983. 317p.

SILVA, J. L. Werneck da. A deformação da História; ou para não esquecer. Rio de Janeiro: J. Zahar, 1985. 96p.

SILVA, Marcos A. da (Org.). Repensando a História. Rio de Janeiro: Marco Zero, 1984. $141 \mathrm{p}$.

SNYDERS, Georges. Escola, classe e luta de classes. Lisboa: Moraes, 1977. 406p.

TELLES, Norma Abreu. Cartografia brasilis ou esta história esta mal contada. São Paulo: Loyola, 1984. 156p.

THOMPSON, E. P. A miséria da teoria, ou um planetário de erros; crítica ao pensamento de Althusser. Rio de Janeiro: Zahar, 1981. 231p. 